\title{
Ayangbai: Maternal Culture Symbol of the Bai Nationality
}

\author{
Chunji Zhang \\ Sichuan Fine Arts Institute \\ Chongqing, China \\ Ceramic Institutes of Jingdezhen \\ Jingdezhen, China
}

\begin{abstract}
Ayangbai" was a rock carving excavated in the 11th year of Tianqi's reign, the 10th king of Nanzhao, which was located in Shizhongshan Grottoes in Shibaoshan $30.5 \mathrm{~km}$ southwest from Jianchuan County, Dali Bai Autonomous Prefecture, Yunnan Province. The paper introduces the specific shape of Ayangbai Rock Carving and the meaning of Ayangbai and discusses the cause of Ayangbai becoming symbol of maternal culture.
\end{abstract}

Keywords-Ayangbai; the Bai nationality; maternal culture; symbol

\section{The Shape Of AyANGBAI}

It is located in Shizhongshan Grottoes in Shibaoshan $30.5 \mathrm{~km}$ (straight-line distance of $20.5 \mathrm{~km}$ ) southwest from Jianchuan County, Dali Bai Autonomous Prefecture, Yunnan Province, which was excavated from the 11th year (AD 850) of Tianqi's reign, the 10th king of Nanzhao to the 4th year (AD 1179) of Duan Zhixing's reign in Daili Kingdom (AD 1179), which lasted over 300 years. So far 16 grottoes and 139 sculptures have been found, among which 5 grottoes are now in Sahdengjing District, 9 are in Shizhong Temple and 3 are in Shiziguan. "Fig. 1"

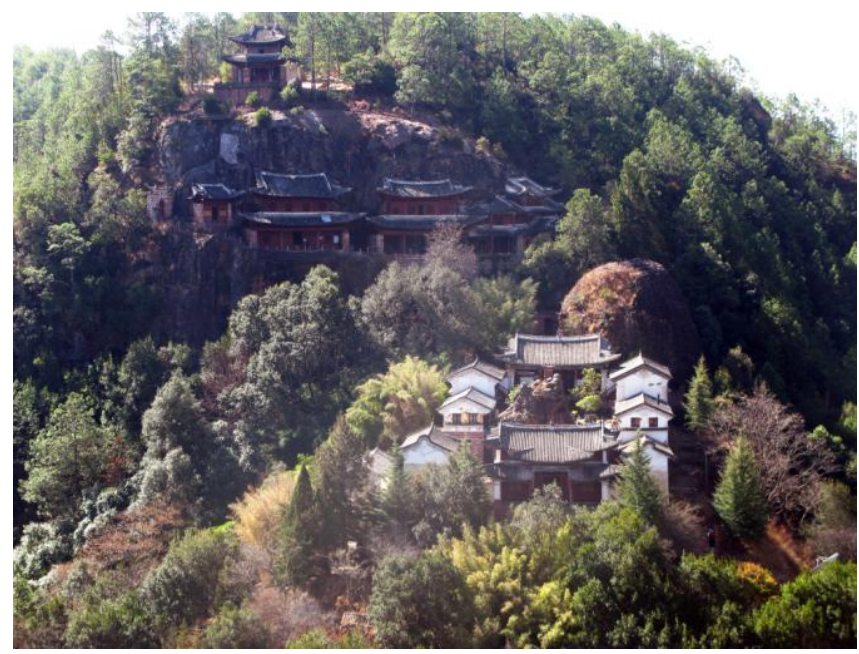

Fig. 1. Panorama of Shizhongshan Grottoes
Shizhongshan Grottoes have the most sculptures, most abundant themes and greatest carving art among grottoes in Yunan, which are alto the ones protected best. Among 16 caves in Shizhongshan Grottoes, the most special one if Ayangbai, the 8th cave. "Fig. 2", "Fig. 3", "Fig. 4", "Fig. 5", "Fig. 6"

The 8th cave of Shizhongshan Grottoes is located in the most east side of upper cliff of Shizong Temple area. There is an inscription on the top of the shrine with 9 lines of preface in regular script: the lord in the ancient times is in Lingtaifa? daolan /one like Avalokitesvara can have four cycles of life/ the master is busy invisibly.../...its figure sit/shangshibu...Heavenly Kings' good words/kept in function of.../daiciming...endless fortune/generations of descendant...endless/worked in 4th years of Shengde...recorded on 3rd of the eighth lunar month in the year of Ji Hai.

On the left, right and top of the inscription carved lotus, lotus leaves and tassels, on the bottom of the frame carved 3 cloud patterns, which form a half-round shrine lintel. It can be inferred that the inscription is caved at the same time with shrine figures, and the year in the frame shall be the year when the shrine figure was caved.

In the middle of the shrine is now a tapered relief, in the middle of which carved a groove, namely "Ayangbai" (female genitalia) called by local people. As far as the overall shape is concerned, the tapered article was roughly caved. There was a lotus platform under the tapered article, which is not damaged, and under the lotus platform was a girdling square base.

There is respectively a figure of sitting Buddha on the left and right wall of the shrine.

There is respectively one shrine of Heavenly Kings on the two sides out of the shrine. The two Heavenly Kings had similar forms, whose head and face were damaged, and the existing head and face were recaved in 1953. Ayangbai was $0.42 \mathrm{~m}$ high, which was the obscure appellation of female genitalia in the language of Bai Nationality. Ayangbai was in the same row of Buhhda, Bodhisattva and Heavenly Kings, and was consecrated on the lotus platform, accepting the worship of believers. Her image was a unique entity of female genitalia in the art of Chinese Buddhism Grottoes. 


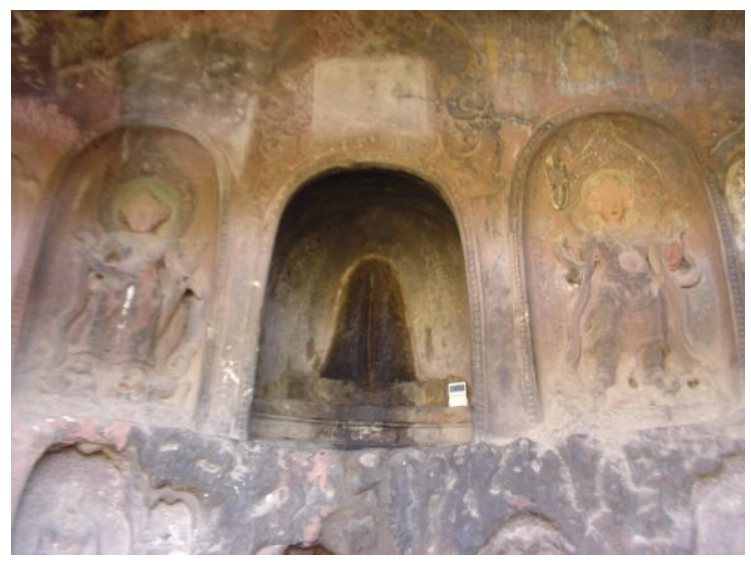

Fig. 2. The 8th cave in Shizhongshan Grottoes

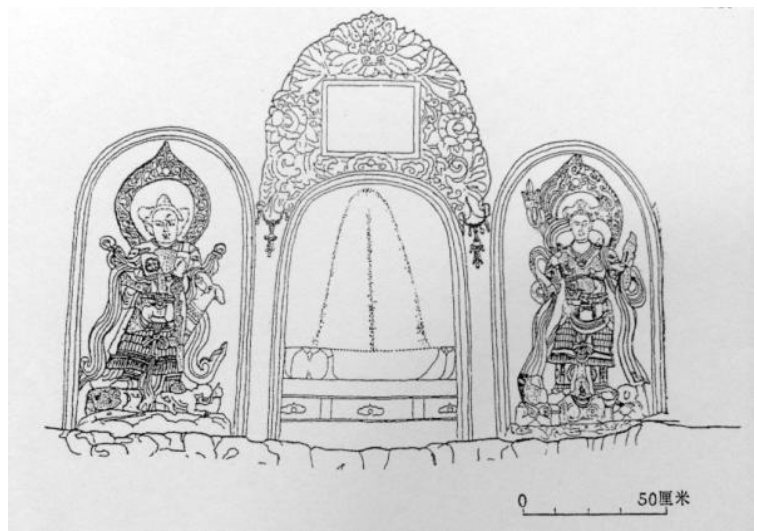

Fig. 3. The vertical picture outside the 8th cave in Shizhongshan Grottoes

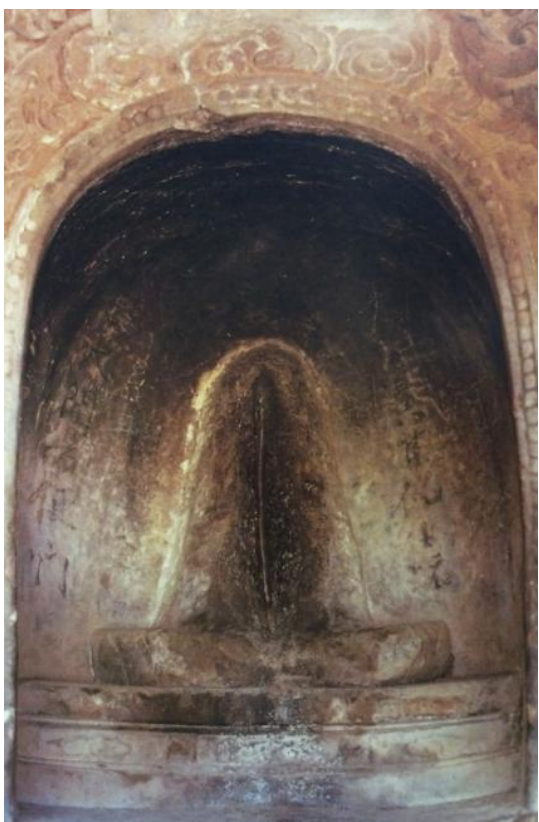

Fig. 4. "Ayangbai" in the 8th cave in Shizhongshan Grottoes

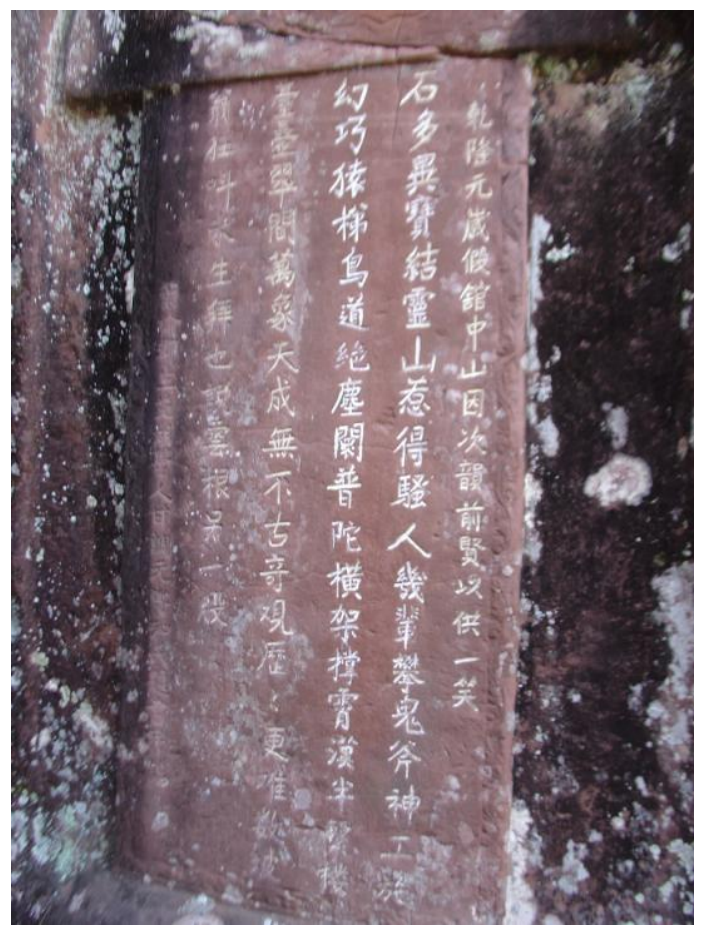

Fig. 5. Side inscription of "Ayangbai"

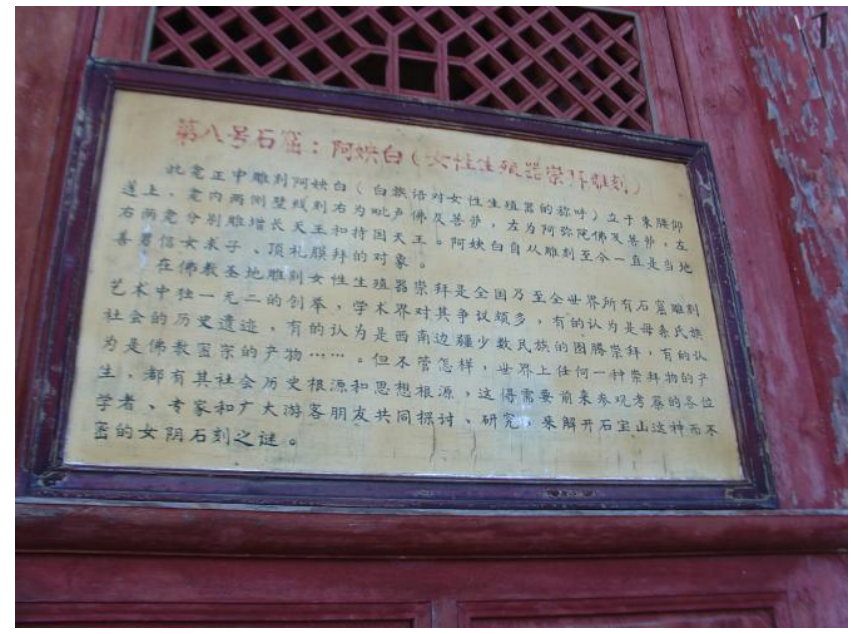

Fig. 6. Text commentary plate of "Ayangbai"

\section{The MEANING OF AYANGBAI}

The clear explanation of Ayangbai can not be found in the language of Bai Nationality, and scholars have various opinions on it.

First of all, for the explanation of Ayangbai, Zhang Xu thinks that: how to explain "Ayangbai" on earth? People of Yi Nationality have mostly consistent explanation of "Bai", which is the female genitalia. But there are many statements of "Ayang". Some people say "Ayangbai" means "Amaibai" in the language of Yi Nationality, namely female genitalia... (People of Bai Nationality) say that "Bai" was the ancient name of female genitalia in the language of Bai Nationality... 
Some people say that "Bai" is the changing pronunciation of "Pi", which refers to female genitalia, namely "Xi'naipi" wrote on the top of the cave. "Ayang" is the appellation of infant in the language of Bai Nationality, if so, "Ayangbai" can be explained as vulva to give birth to infant, elegantly speaking, the place where the infant comes out, or the thing to give birth to baby. 2

$\mathrm{Li} \mathrm{Fa}$ thinks that it shall be the mistake of "Anyangbai." $\mathrm{He}$ says that: "Anyangbai' refers to the female genitalia in the language of Bai Nationality, and the word's meaning reflects the inner connotation of female domination... 'Ayangbai' or 'Ayingbai' shall be the mistake of the pronunciation of 'Anyangbai'. The person who recorded words in the language of Bai Nationality with Chinese language, which will definitely influence the correct explanation of the word (because the tone is to distinguish the word's meaning). Thus people of the Bai Nationality can not understand its meaning, neither can the person who explains it."3

Jiang Yinlian says in the paper "Legacy of reproduction culture in Erhai area" that: "This rock carving of female genitalia is called as 'Ayangbai'. This word was earliest seen in the book 'Jianchuan Grottoes' written by Song Boying after inspecting Shibaoshan Mountain in early 1950s, but the explanation of 'Ayangbai' was a little vague. In 1956, NPC sent Research Group of Yunnan nations to write the paper 'Summary of research on historical relics and social economy of Nanzhao and Dali kingdoms'. The paper said that: '... 'Ayangbai', the rock carving of the female genitalia in Shibaoshan Mountain, Jianchuan, 'Ayang' refers to 'girls' in the language of Bai Nationality, and 'Bai' refers to female genitalia. There is another appellation of this among local people of Bai Nationality, which is 'Xipi'nai', meaning 'dead stuff of giving birth to baby'. Because the clear explanation of 'Ayangbai' can not be found in the language of Bai Nationality, scholars have put forward various opinions on it. Some people think 'this is a language of Yi Nationality, meaning the female genitalia'; some people think 'Bai' is the changing pronunciation of "Pi", which refers to female genitalia, and "Ayang" is the appellation of newly born infant, which can be explained as the crack of giving birth to baby; some people think "Ayangbai" is the transliteration in Chinese language, which does not clearly express the tone of the language of Bai Nationality due to inaccurate record, and this will definitely influence the correct explanation of the word, so some people of Bai Nationality can not correctly explain its meaning. And they think the correct pronunciation is 'Anyangbai', in which 'Bai' refers to female genitalia, 'Yang' refers to giving birth to baby. Thus, 'Anyangbai' is the female genitalia in the language of Bai Nationality, and the word' s meaning reflects the inner connotation of female domination." 4

Lu Jiarui thinks that Ayangbai refers to "place of baby girl with water and grass" or "crack of baby girl", which is the obscure antonomasia of female genitalia.

We can see from the above explanation that "Ayangbai" is explained as the female genitalia in both the languages of Bai and Yi Nationalities. In my opinion, "Ayang" in "Ayangbai" is the appellation of female genitalia among people of Bai Nationality- "Anv" refers to girls, women, and 'Bai' refers to laying out, unfolding, or "breaking off", and together Ayangbai means girls unfolding legs, meaning the genitalia of women or girls. In the language of Bai Nationality, there are also some other appellations of female genitalia, such as "Zade", "Pi'nai" and "Geide" (chicken or small chicken). On the shrine lintel near the rock carving of Ayangbai carved "Xipi'nai', in which "Xi" means dying and immovable in Chinese language, and "Xipi'nai" can be directly translated as dead female genitalia, which is dirty word.

"Endless fortune", "gather living way widely, widely opening convenient door" also clear reflect that "Ayangbai" refers to female genitalia.

\section{The Cultural Symbol OF AyangBaI}

Idols of female genitalia similar to "Ayangbai" can often be seen in many folk customs, which is especially common in southwest area where the Bai Nationality is located. In Gejiu, the capital of Hani and Yi Autonomous Prefecture in Honghe, Yunnan, Laoyinshan Mountain got the name for having a spot like an unfolding female genitalia on its cliff. In Yanyuan County, Sichuan, there is a hole of "throwing for baby" on Qiansuo Rock, and it's said that people who can throw stones into the hole can get pregnant. There is also a "hole of touching for baby" on Guanyin Rock, Xide County, Liangshan, people who pray for children put their hand into the hole after burning incense and kowtowing, those who touch the stone can have son, and those who touch sand can have daughter. There are also two famous rocks of genitalia of Ji'nuo Nationality in Ji'nuoluoke Mountain in Jinghong County, Xishuangbanna, Yunnan, one is in 'Mushan Mountain' in Huangping, and the other is in Duomei. There is even a salt well in Yunlong County, whose external shape is like a female genitalia very much ans salty water flows out of it. There is certain relation among so many idols of female genitalia around Jianchuan, Yunnan, the reason why Ayangbai appeared in Jiangchuan area, and primitive culture of Bai Nationality.

Totally different from Han Nationality, Bai Nationality calls the heaven as "Tianmu", in the concept of heaven and earth of the Bai Nationality, the heaven also symbolizes "maternity". In the myths of creating the world of the Bai Nationality, the heaven, sun, moon, wind, rain.... are all created or dominated by women. In stories of the Bai Nationality such as "separating heaven from earth", "Avalokitesvara covering the heaven", "origin of Fengyu Dam", "Mother Avalokitesvara" covered the heaven with her square kerchief, blew the wind from the opening of the kerchief she cut, dropped the rain evenly from the seam of the kerchief. This Avalokitesvara was not only the creator of the heaven, but also the dominator of wind and rain. And the sun and moon were two sisters.

In daily life of families of Bai Nationality, the status of mother is very high, who are called as family mistress. All the domestic affairs are hosted and arranged by family mistress. In the custom of weddings, they can take in a son-in-law no matter whether they have a son, which is called as "taking in a son-in-law for favor" in the language of Bai Nationality. The son and the son-in-law have the equal right of inheritance to the family property. The women don't change their names 
when they are married, and men have to change names when they are taken into a family as son-in-law, and their children's names shall also follow the mother. In the custom of funeral, there is a saying of "the funeral of father can executed within people's means, but people shall kneel to execute the funeral of mothers, as for the title on the mother's tombstone, if the father's last name is Zhao and the mother's last name is "Wang", that will be "Mother Zhao of Wang's", which highlights the word "mother". And the power of mother's brother is also great thanks to the tradition of "mother dominating" of the Bai Nationality. In the language of Bai Nationality, there are many phrases that are dominated by "mother" and taking "mother", which becomes a feature of phrases with emotional color in the language of Bai Nationality. When people of the Bai Nationality meet great happiness or great grief, they can't not help calling "mother", which becomes a common subconsciousness.

In folk literature of the Bai Nationality, legendary stories, folk poems and even folk songs reflect a feature of feminine literature.

Buddhism in Yunnan has deep local nation features. "Yunnna Esoteric Buddhism" with colors of witch doctrine, ghost doctrine and esoteric buddhism, Bai Buddhism believed by "Mothers' club" organized by middle and old aged women, Bai Taoism, and even Duoxibo doctrine, the original religion of Bai Nationality worship Avalokitesvara very much. In the language of Bai Nationality, Avalokitesvara is called as "Mother Avalokitesvara". In legend, Mother Avalokitesvara was the "first ancestor mother" and "creator" who separated heaven from earth" for Bai Nationality, and even the establishment of Nanzhao and Dali kingdoms got help from Avalokitesvara.

There is a song meeting every year in Shibaoshan Mountain, Jianchuan, Dali, which offers several days of time for young men and women having or not having lovers to falling in love. These people are not limited to unmarried men or women, those married people can also enjoy the same happy time, which is similar to "commit adultery in mulberry fields" such as "Du" in Zhou Dynasty, "mulberry fields" in Song Dynasty and "Yunmeng" for State Chu.

Ayangbai's appearance on Shibaoshan Mountain, Jianchuan can not be separated from the important status of Shibaoshan Mountain in the history of Bai Nationality. Jianchuan is the most important producing area of salt in Nanzhao Kingdom, also the place which Nanzhao and Tubo fought for. Shibaoshan Mountain was on the north-south passageway, namely an important location on the Ancient Tea Horse Road. It was both a trade channel and a channel to spread Buddhism, and also one of the most important routes that connected the northwest area of Yunnan to hinterland, Tibet, Burma and India. Shizhongshan Mountain may once be a place of hunting and leisure for royals of Nanzhao. Building a grotto of Buddhism in such a resort of hunting and leisure was possible for Nanzhao Kingdom which believed Buddhism. There is also literature that conjectured that Shizhongshan Mountain might be the location of royal mausoleum of Nanzhao and Dali Kingdoms.
There are now two different opinions on the time when Ayangbai appeared, and all the disputes gather to whether the rock carving of "Ayangbai" was an original figure or it was changed later? People with positive opinion think that the rock carving of female genitalia in Jianchuan acted as a primitive production idol. In local area, due to the long-term worship of women, a deep female genitalia was left on the front stone plate, which reflected that it was not new. The order of group sculptures from Ayangbai to Ksitigarbha Bodhisattva makes people with positive opinion even surer that they are arranged in the order of eternal cycle of birth and death in Buddhism. People with negative opinion think that the lotus base of Ayangbai is now weathered, but its fine carving can still be seen, which is totally different with the carving of Ayangbais. People with negative opinion think that there was formerly a Buddha sculpture in the position of Ayangbai, and whether it was Sakyamuni, Avalokitesvara or Mandkesvara was realted to local culture, after the Buddha sculpture was damaged, people set up Ayangbai, the sexual symbol worshiped by local people. However, based on the words "Lanruo Avalokitesvara... creator" on the inscription remaining, combined the former Buddha sculpture and inscription of Avalokitesvara, the latest archaeological report on Jianchuan Grottoes (1999) thinks that the former sculpture might be Avalokitesvara, and Ayangbai appeared after it was damaged.

Regardless of the time or condition pointed out in the research report, Ayangbai was a female genitalia indeed, which appeared in the grotto with Buddha sculptures and accepted local people's worship with them. People of Bai Nationality there would recite a song of sacrifice before kneeling to Ayangbai, the lyric of which is jinl on mail, dexfvrx guail ; cainl dainrx me , me dainrx bainl, dainrx zil bainl nail nail", meaning: "frog bloat its stomach; the pan beats jar, the jar is broken, and comes into Pannainai (onomatopoeia)." After reciting, they would kneel after hearing the echo from the opposite mountain, and put sesame oil on "Ayangbai". Such concept of female reproduction worship continues till today. Ayangbai acts as a representative of maternal culture in local area, also a lively symbol of maternal culture, which can not be denied.

\section{REFERENCES}

[1] “Jianchuan Grottoes: brief report on archaeological survey in 1999" (Group of Archaeological Research on Jianchuan Grottoes of Department of Archaeology of Peking University and Department of History of Yunnan University).

[2] “Discussion on Nanzhao Culture” . Chief editors: Yang Zhonglu, Zhang Fusan, Zhangnan, (Yunnan People's Publishing House, 1991.5).

[3] "Jianchuan Grottoes"(Yunnan Art Publishing Pres, 1985.9.) Written by Ouyang Chun (the Bai nationality), photographed by Chen Pu (the Yi nationality).

[4] “Jianchuan Shizhongshan grottoes: southern treasure" (Yunnan Art Publishing Pres, 1998.8), compiled by Culture and Sports Bureau of Jianchuan County, Yunnan.

[5] “'Ayangbai': code of 'maternal culture' of Bai Nationality” Lu Jiarui (Bai Nationality) (paper in International Seminar on Jianchuan Shizhongshan Grottoes in Yunnan).

[6] 'Explaining 'Ayangbai' again", Yang Xinqi (paper in International Seminar on Jianchuan Shizhongshan Grottoes in Yunnan). 
[7] “'Ayangbai' and reproduction worship of Bai Nationality", Liu Huanling, Jiang Zhida (paper in International Seminar on Jianchuan Shizhongshan Grottoes in Yunnan)

[8] "On cause of Jianchuan Shizhongshan Grottoes", Duan Bingchang (Bai Nationality), (paper in International Seminar on Jianchuan Shizhongshan Grottoes in Yunnan) 